\title{
'Not a Problem Until it Becomes a Problem': A Qualitative Study of Values and Risks of In-house Family Ties in Swedish Workplaces
}

\author{
I Katarina Haugen' \\ PhD, Senior Lecturer, Umeå University, Sweden
}

\section{Kerstin Westin}

PhD, Professor, Umeå University, Sweden

\begin{abstract}
In-house family ties at workplaces occur in most contexts, and are associated with both advantages and disadvantages. On the basis of 40 interviews with human resource managers at Swedish workplaces, the values and risks of in-house family ties and their importance within the workplace are analyzed jointly, thus allowing for a holistic perspective. The interviews reveal values and risks on a strategic level, for day-to-day operations, for the social work environment, and on the level of individuals. Crucially, even when in-house family ties are perceived as uncomplicated, there is a latent risk that problems might arise. The interpretation of the role of in-house family ties is also strongly related to whether they are paired with asymmetrical (vertical) power relations. It also depends heavily on the chosen perspective - that of the organization, the social work environment, the individual, or the broader society — and the perceived advantages tend to come with corresponding inverted disadvantages.
\end{abstract}

\section{KEY WORDS}

Family networks / nepotism / qualitative interviews / social work environment / work-family relationships / working life

DOI

10.19154/njwls.v6i4.5613

\section{Introduction}

he presence of in-house family ties at workplaces, be it the owner's relatives or family ties among the employees (Agrawal et al., 2008), has received much scientific attention in areas such as industrial and organizational psychology, business administration, and political science. National legislation regulating family-based recruitment in public offices and companies is in place in most countries (Žulová, 2015). In Sweden, for example, legislation counteracts family-based recruitment and favors in public administration (Förvaltningslag/Administrative Procedure Act, 1986). In the private sector, companies can establish anti-nepotism policies (e.g., Reed, 1988; Lokaj, 2015;

\footnotetext{
${ }^{1}$ Corresponding author, Address: Department of Geography and Economic History, Umeå University, SE 90187 Umeå, Sweden; Phone: +46 9078658 98; E-mail: katarina.haugen@umu.se
} 
Žulová, 2015), but both the extent and efficiency of these are debated. Moreover, adhering to legislation can be motivated by wanting to avoid litigation rather than by actual commitment to the objectives of the legal framework (Koivunen et al., 2015). In Sweden, of the 4.3 million employed (or self-employed) in 2012, the number of family relations (including kin outside the immediate household) was 620,000. This means $14 \%$ family and kin ties at an average Swedish workplace (Haugen et al., 2016).

In-house family ties exist in workplaces in different contexts, albeit to different extents and under partly different conditions. Sweden, a modern democracy, constitutes the case in this study. Although the context-in terms of, for example, legislation, economic preconditions, employment conditions, and social security systems-is specific to Sweden, the reasoning of employers and employees and the importance of, for example, different social mechanisms can be expected to hold certain similarities to that in other countries, and across organizations in different contextual settings. On the basis of qualitative interviews with informants in organizations in the Swedish labor market, the aim of this study is to shed light on how the values and risks associated with in-house family ties and family referral recruitment are perceived.

Following this introduction, the paper proceeds with a review of previous research on the impact and importance of in-house family ties. Next, the approach to data collection and analysis is described. The results are then presented based on different levels of analysis, and supported by illustrative excerpts from the empirical material. The final section contains a concluding discussion focused on different perspectives on in-house family ties.

\section{Literature Review}

Several studies have found support for the positive effects of in-house family ties in recruiting and at work after recruitment. Following the theory of exit and voice (Hirschman, 1970), which postulates that when the performance of an organization deteriorates its members can react by either leaving it (exit) or expressing their concern (voice), Ertug et al. (2014) argue that employees who are kin to other employees are more apt to voice their disagreement than to exit the firm. The existence of family ties has also been shown to have a positive effect on performance, measured as per capita value added (Korang et al., 2016). Firm survival can also be affected in a positive way (Ertug et al., 2014).

Hiring family members, particularly for the small firm, can be a way to attract and retain cheap labor, and an effective and fast way of recruiting (Abdalla et al., 1994; Vveinhardt \& Petrauskaité, 2013); and owners who have hired family can avoid the time and cost of monitoring after recruitment, thus reducing agency costs (Dyer, 2006). Hiring family members can be a way to enhance a positive family-oriented environment; the continuation of existing values and skills in the organization can be ensured as a result of knowledge transmission from one generation to the next (van Hooft \& Stout, 2012); and social connections, such as family and friends, can add value to an organization (Jones $\&$ Stout, 2015). Indeed, heritage has been identified as one of the factors contributing to nepotism. A second factor entails motives and preferences influenced by family, while a third is the transfer of human capital as a result of exposure in the family (partner). Further, when hiring a family member, it is likely that this person will be grateful for the job and perform well (Hernandez \& Page, 2006, in van Hooft \& Stout, 2012). Particularly 
in new firms, Ertug et al. (2014) argue, kinship can positively affect the degree of solidarity within the organization. When it comes to new firms, it can be a hard task to recruit non-kin employees as the risk of failure is often evident, and kinship recruitment may therefore be the 'only' option for the employer (ibid.).

Work and home have been seen as two separate spheres of life in work-family theories, whereby home not only holds diverging emotive expressions such as love and empathy but also negative expressions like anger and jealousy. At workplaces, on the other hand, emotive behavior has rather been suppressed or discouraged (Muchinsky, 2012). The division between these two domains is challenged when family members are recruited or family relations are established at a workplace (e.g., coworkers falling in love). Family ties at a workplace, particularly members of the same household (e.g., spouses, parent-child), partly dissolve the border between private and professional life. This has been argued to be beneficial in some respects. Attempts to integrate work and family life can be a motive for hiring close family (Masuda \& Visio, 2012). This can be a way to make one's whole life easier, but at the same time, it can transform into workfamily conflict (ibid).

The word nepotism has a distinctly negative connotation due to its close relationship with corruption and anti-democratic practices, and because it implies that family ties go before merits and competence (e.g., Padgett \& Morris, 2005; Fu, 2015). Several scholars have identified negative effects of family ties in workplaces. When the prevalence of family ties means an overlap in social network, there is a risk that the amount of new ideas and new information will be reduced (Granovetter, 1973; Ertug et al., 2014). When family members are hired, it is argued that family loyalty and obligations are placed over loyalty to the employer (Pearce, 2015). Nepotism can be detrimental to organizational performance, as it leads to greater coworker distrust, as well as greater dissatisfaction, fearfulness, and obsequiousness in employees (ibid). Performance can also be affected by conflicts within the family (Dyer, 2006). The risk of other employees' negative perception has also been suggested, for example, that nepotism signals unfairness (Padgett \& Morris, 2005; van Hooft \& Stout, 2012) and affects employee moral negatively (Padgett \& Morris, 2005; Fu, 2015). Pearce (2015) goes so far as saying that 'nepotism and cronyism damage exactly the kinds of social relationships that make for a humane and tolerable workplace' (p. 43). It has even been asserted that nepotism and dysfunctional behavior in organizations can lead to deviant and dishonest decisions by management, which counteracts the ethical values corporate social responsibility (CSR) embraces (Vveinhardt \& Zygmantaite, 2015).

Negative attitudes toward family ties can also concern the perspective of the person who is provided with benefits through their family connection: the nepot. The suspicion of having been hired for family reasons rather than competence can affect how the nepot perceives his/her effort (Abdalla et al., 1995). Being linked to the owner, manager, or other person with some degree of power in the firm might discourage the nepot from participating in discussions of firm organization and performance, out of fear that regardless of how valid his/her ideas are they will be valued negatively (Padgett \& Morris, 2005).

For obvious reasons, family ties are frequent in family firms. Family firms have several unique features and resources, often referred to as 'familiness', which can be defined as involvement (the presence of family in the firm), essence (how family members behave in the firm), and organizational identity (how the family views and defines the firm, e.g., a shared understanding) (Zellweger et al., 2010). When family members view the firm 
as an extension of the family, they strive for and thus create and maintain a positive organizational identity; it contributes to a successful business. Promoting a business as a family firm sends the message of trustworthiness, quality, and customer sensitivity to customers, suppliers, and financers. Part of the marketing and branding therefore lies in being a family firm (Zellweger et al., 2010). There is evidence that family firms perform better than non-family firms (Anderson \& Reeb, 2003). However, other studies point in the opposite direction: that firm assets can be used for personal goods and services and thus drain the firm of financial resources (Dyer, 2006), and that family conflict transcends to workplace conflict (Abdalla et al., 1994).

\section{Data and methods}

Because this paper is focused on perceptions of the values and risks of in-house family ties, an informant interview approach was chosen. This allows for tapping into 'insider' perspectives and understanding ways of thinking and reasoning around the issue within organizations. The style of the interviews was semi-structured, open-ended, and largely explorative in focus, given the relative scarcity of prior qualitative research in relation to the aims of the study.

We conducted 40 interviews with 44 human resources managers and executives (some of the interviews had double informants) at a wide range of workplaces in Sweden (Table I). The fieldwork was carried out between May 2014 and February 2015. The interviews lasted an average of just under 1 hour, and ranged from just over 30-90 minutes. Informants were recruited within organizations of different size in different regions, with the intention of achieving variation (e.g., Coyne, 1997) within the group and thereby attain rich data.

Informants responsible for recruitment within the organizations were identified and contacted through 'gatekeepers' (Feldman et al., 2003b). Most of the informants

Table I Overview of the interview material and the organizations the informants represent

\begin{tabular}{|c|c|}
\hline Geographical setting & $\begin{array}{l}17 \text { metropolitan areas } \\
4 \text { large cities (>100,000 inhabitants) } \\
8 \text { medium-sized cities (50,000-100,000 inhabitants) } \\
4 \text { smaller cities ( } 10,000-50,000 \text { inhabitants) } \\
4 \text { small towns (2,000-10,000 inhabitants) } \\
3 \text { rural areas }\end{array}$ \\
\hline Sector & $\begin{array}{l}30 \text { private (of which } 9 \text { family firms) } \\
10 \text { public ( } 6 \text { municipal; } 4 \text { state) }\end{array}$ \\
\hline $\begin{array}{l}\text { Line of business } \\
\text { (non-exhaustive) }\end{array}$ & $\begin{array}{l}\text { Industry (technical; wood; food), primary, retail, tourism, restaurant, hotel, financial } \\
\text { services, architecture, communication, life sciences, cleaning services, transporta- } \\
\text { tion, logistics, public services, state authority/public utility, municipal administration }\end{array}$ \\
\hline $\begin{array}{l}\text { Organization size } \\
\text { (Eurostat 2016) }\end{array}$ & $\begin{array}{l}17 \text { large (>250 employees) } \\
13 \text { medium-sized (50-249 employees) } \\
6 \text { small ( } 10-49 \text { employees) } \\
4 \text { micro (<10 employees) }\end{array}$ \\
\hline Informants' sex & 27 women; 17 men \\
\hline
\end{tabular}


had firsthand experience of in-house family ties, either professionally or as personally involved in such circumstances. In some cases, this experience derived from previous jobs, although the main focus was on the conditions in the current organization. The informants' represented the employer's perspective, and although their accounts are mostly concerned with in-house ties among the employees', there are also cases where they reflect upon personal experiences of the issue.

Prior to the interviews, the participants received an interview guide presenting the main issues to be covered during the interview, to give them an opportunity to prepare. The interview guide covered organizational recruitment processes and specifically the use of family referral recruitment and the extent, consequences, and management of in-house family ties within the organization. While ensuring that the themes of the interview guide were covered, the wording of the questions varied across interviews as a consequence of the flexible, semi-structured approach, and the informants were encouraged to bring up additional issues that they deemed relevant ( $\mathrm{Qu} \&$ Dumay, 2011).

The rationale for including a number of 'explicit' family firms was an assumption that there could be a higher level of openness to discussing the potentially sensitive and controversial issue of in-house family ties in firms where the presence of family members in the organization is a self-evident feature. Most interviewees were approached through 'cold calling' (Feldman et al., 2003a). In addition, four informants were chosen through inquiries within the researchers' personal social networks. These informants represented firms known to have some degree of family ties present in the workplace. Finally, snowballing was also used as a way of finding additional informants based on the informants' networks. The interviews were conducted face to face, except in six cases in which telephone interviews were done.

The interview material was collected and treated under the principle of confidentiality. The interviews were recorded with the informed consent of the informants and were transcribed verbatim (with the exception of details that could reveal the identity of the organizations and/or informants).

The data were analyzed thematically (Braun \& Clarke, 2006) in relation to the aim. To identify patterns in the data, in the initial phase, the transcribed material was coded line-by-line using MAXQDA software for qualitative analysis. Over the course of the coding process, the codes were simultaneously sorted into preliminary categories, which were also continuously revised and refined. Analytic memos (Saldaña, 2016) outlining and interpreting the developing themes were written continuously to provide a basis for further analysis. Following the coding process and initial definition of themes, the themes underwent a final revision to adjust the fit to the data and aim, with an emphasis on conceptualization and connections between themes.

\section{Results}

\section{Overarching Issues: Asymmetrical Power Relations and Latent Risk}

Two overarching core themes are connected to how the informants view the issue of in-house family ties as well as which strategies (if any) they consider appropriate for managing the matter. 
First, the informants' judgments are strongly influenced by whether there are asymmetrical power relations or dependency situations at play, and it is when this is the case that the matter of in-house family ties is brought to a head. Many informants argue that it is truly only in cases where there are hierarchical differences, that is, vertical ties (Ertug et al., 2014), between the parties in a situation that the risk for special treatment and conflicts of interest and loyalty become potential problems. Moreover, if two individuals belonging to the same family are both in an executive position, there is an inappropriate concentration of power within that family. In a situation characterized by asymmetrical power relations family ties can become a threat, whereas if the relatives in question are equal in position and power at work, their relationship is much less problematic or even a non-issue:

Position of dependence, that's when one of the parties has some form of power or [is] a manager, [in the] leadership, can exert power so to speak. /.../ [But if] you work, without having a position of dependence but you have a relationship /.../ that's not a problem. /.../ It's an important difference, position of dependence or not. [\#13; large city; technical industry; large organization; male informant]

[When there are no asymmetrical power relations] there [is] no conflict of interest. He can't use that position, he doesn't determine his brother's wages for example. That never would've been acceptable. /.../ That's a rule. [\#20; metropolitan; technical industry; large organization; female informant]

The second overarching key issue lies in the latency of family-related problems within an organization. In most of the informants' narratives, there were no de facto problems. However, due to the mixing of private and work relations, there is a heightened risk that problems might surge, and that if (when) they do, they may escalate and lead to repercussions beyond proportion due to the family dimension (cf. Masuda \& Visio, 2012):

You have to think about it and handle it before it becomes a problem, because as long as it's fine it's /.../ but once there's a conflict of interests and it becomes, it affects the team, then we go down in performance and delivery and in the end our customers are going to notice. /.../ It's when things go wrong - that's our point of departure, as long as it's fine then it's fine. There's no problem. But when you're faced with a situation where there's something that isn't working, then it's something different when there's kinship. [\#32; metropolitan; travel agency; large organization; female informant]

If it's possible I'd prefer to refrain from having relatives [among the staff]. I'd [prefer that], in case problems were to arise. They usually don't, but if they do then you have serious problems. [\#12; small town; retail; large organization; female informant]

The focus of the problem can be, for example, a conflict between coworker relatives or, alternatively, other misguided or erroneous assumptions about irregularities (conflicts of interest, special treatment, etc.). Hence, in-house family ties are not necessarily problematic per se. However, the risk that problems may emerge-or even simply the suspicion that they might—can be a reason enough to take a cautious stance in regard to the issue. It is not a problem-until it becomes a problem. 


\section{Overall, Strategic Level}

Hiring employees' family members means hiring people who tend to have prior knowledge and understanding of the working conditions within the organization (cf. van Hooft \& Stout, 2012). Through socialization with the insider relative, the candidate gains insight into the work and what expectations are placed on the workers: that is, transferal of tacit knowledge. Given that the applicants have this knowledge, they make an informed choice when entering employment within the organization, which improves the chance that they will fit into the work context and perform well. Thus, the risk of hiring the wrong person for the job is reduced:

You have a lot of initial knowledge of what the individual in question is capable of, and that person also understands the task very well. Because maybe he's discussed it at the dinner table. [\#19; metropolitan; life sciences; family firm; medium-sized organization; male informant]

Some informants argue that family can be a 'success factor' in business, whether in terms of family ownership, family employees, or a sense of 'familiness' as a social feature (cf. van Hooft \& Stout, 2012). For instance, there are stories of how major corporate groups have built their success on family ties, and how the family feature can be an important part of a firm's brand and be used in marketing (cf. Zellweger et al., 2010). Informants in both family firms and other types of organizations reflect upon this matter:

All the major corporate groups are based on family networks... in different ways. And they've been built up over the course of maybe a hundred years back, four-five generations, so if you look at it that way [family networks] are the foundation for the firm's, well, its position on the market. [\#26; metropolitan; state authority; large organization; female informant]

The familiness - that we're a family for one thing, but also the atmosphere. I think we've really gained a lot from that /.../ the customers think /.../ it's a big advantage. [Major international customer] likes to introduce us as a family and... that this is family-run and family-owned and family... /.../ I think you feel like there's a better chance of getting good service and being treated well if it's the family, I mean if the person providing the service is also the owner of the service and everything. [\#8; rural; tourism; family firm; small organization; male informant]

When employees are recruited through personal family networks, the new recruits can be assumed to act differently compared to how others without insider connections would. The workers can be more inclined to perform well at their jobs, out of gratitude for being given the opportunity. Similarly, the employer can often expect a higher level of dedication and loyalty toward the organization (cf. Hernandez \& Page, 2006, cited in van Hooft \& Stout, 2012). Caring about your job and employer is a way of caring about your personal relationships, as well as a way of reciprocating the favor you have received. Hence, some informants argue that recruitment through family referral and long-term relationships guarantees employee responsibility, seriousness, and performance. This becomes particularly clear among family firm informants: 
When everything's built on personal relationships before employment then it's... It has to be like this! There must be a better chance you'll feel a sense of responsibility both towards the employer and towards your contact who recommended you for the job. [\#8; rural; tourism; family firm; small organization; male informant]

If we help our staff who work in this firm then we know they'll be there for us and help us if we need it, and they'll pour their hearts into the job. [\#35; metropolitan; cleaning services; medium- sized organization; female informant]

On a somewhat similar note, hiring employees' family members can also be argued to be an expression of concern for the staff and their well-being on the part of the organization. Some informants speculate that this concern and sense of responsibility can even be stretched to the scale of the local area, a sort of CSR in relation to the local population (cf. Vveinhardt \& Zygmantaite, 2015). Taking care of staff and their families can be seen as an investment, for example, a way of ensuring loyalty. Several informants also see value in helping youth (employees' children) through an introduction to working life, allowing them to gain a foothold on the labor market. If their parents' employer can offer a short-term position, part-time work, or an internship, this gives them valuable experience and initial merits for their future careers. One informant even argues that this constitutes a benefit for society more generally, for instance, in terms of the functioning of the labor market or a reduction in youth unemployment:

This is something that helps society, maybe, that we help each other within families, with finding work. [\#29; metropolitan; public utility]

However, the informants also see risks associated with a heavy emphasis on family referral recruitment. This concerns the organization's long-term development. Hiring based on recommendations is often the result of taking a shortcut approach to recruitment rather than engaging in systematic and professional, but also time-consuming, recruitment processes. Informants in different organizational and geographical contexts-and who do or do not engage in family referral recruitment-outline that this can be risky and counterproductive for several reasons:

We're completely dependent on external recruitment. And we can't take those kind of shortcuts. /.../ Because otherwise there will eventually be a risk that, the worst thing that could happen to us, that would be if there were no point in applying for a job here because 'you choose the ones you want anyway'. /.../ Then you're in trouble. [\#13; large city; technical industry; large organization; male informant]

If you rely too much on recommendations /.../ then you might miss the opportunity to find someone who could've taken on the role of manager. So the thing is that recommendations can sometimes mean that you get a [person who is] fine for the role [in question] but you haven't thought it through. [\#36; medium-sized city; financial services; medium-sized organization; male informant]

Organizational survival, development, and innovativeness are described by several informants as highly dependent on successful staff recruitment. If recruitment is largely 
based on recommendations and family referrals, there is a substantial risk for a suboptimal outcome. The problem can lie in a lack of plurality of competences, for example, cementing incumbent competences being reproduced rather than complemented with new additions (cf. Granovetter, 1973; Ertug et al., 2014). Moreover, potential applicants may abstain from approaching the organization if they feel there is no chance of being hired if one does not have an inside connection. As a result, the organization risks not being as well equipped to face the challenges and competition, as it might have been with a different recruitment strategy that is strategic in the longer term.

\section{Day-to-Day Operations}

\section{Social control: expectations and demands on the nepot and the facilitator}

The importance of incumbent in-house family ties cannot for the most part be described in simple terms of pros and cons as this is highly dependent on perspective-mainly the nepot's versus the employer's. Family referral recruitment and in-house family ties affect expectations, control, and staff responsibility in the workplace. One clear theme is pressure and demands on the nepot to perform well at his/her job (cf. Abdalla et al., 1995). The expectations on the nepot are bumped up to a higher level than other workers, precisely because their route into employment went via family connections:

The demands placed on me have been disproportional for a very long time /.../I've always felt a ... pressure to show that I'm not here just because I'm a member of the family. Of course I wouldn't be here if I weren't a member of the family, there's no denying that. But that's not why I'm still here. I'm still here because I can contribute something and because I care about this business. [\#19; metropolitan; life sciences; family firm; medium-sized organization; male informant]

This seems to be the case particularly when the facilitator is in an executive position:

I'm hard and maybe a little unfair towards my family, but at the same time I've brought them [into the organization], I'm the one who employed them, and there's no way they'll be given advantages just because they're related to me, and so I'm probably twice as hard on them. [\#35; metropolitan; cleaning services; family firm; medium-sized organization; female informant]

The underlying rationale is to make it clear to the nepot as well as other workers that the nepot is not given special 'VIP' treatment despite the circumstances of their being hired in the first place. Conversely, there may in fact be negative special treatment, with potentially quite substantial negative effects on the nepot's work situation as a result. In addition to the exogenous demands placed on the nepot by the employer, there are additional endogenous pressures that the nepot places upon himself/herself. Showing gratitude for the job opportunity through hard work and dedication is part of this. In addition, finding a job through family referral has the consequence that the nepot is at risk of being scrutinized and questioned, and must therefore prove himself/herself worthy and competent at all times and refute any concerns or doubts as to whether he/she 
is in fact 'good enough'. Performing well and acting responsibly is a way of protecting oneself from suspicion and ensuring a positive personal reputation, particularly in the period immediately after being hired:

The disadvantage I can think of is that initially you're on a kind of probation, you have to perform to, like, show what you've got so that [it is clear to everyone] that you're there on your own merit. [\#21; metropolitan; financial services; large organization; female informant]

I [had] a co-worker who was a really capable guy, whose father was a manager at [firm]. And he'd be reminded of that like countless times every day. And he, it didn't matter how capable he was as long as he was a manager there. Today he's made a career for himself so to speak at [said firm]. But he'd hear this all the time. And I think he thought it was incredibly tiresome /.../ People scrutinize every little detail. [\#22; metropolitan; municipal administration; large organization; female informant]

From the nepot's perspective, these social control mechanisms are mostly described in negative terms, although some individuals may feel motivated and perform well under pressure up to a certain level (Bashir \& Ramay, 2010). Nevertheless, several informants think of this as a positive social mechanism from an employer point of view. The disproportional demands on the nepot may enhance his/her productivity and morale, at least in the short term. However, in the long term, there is a risk that the consequences may turn toward the negative, particularly from a work environment perspective, which is in turn related to employee performance. If the employer were to abuse the nepot's vulnerability in this respect, the outcome could very well be counterproductive.

Another aspect of the rationale for the external or self-imposed demands on the nepot's performance is prestige and protection of the facilitator. Recommending a relative for a position in the organization means putting one's own reputation at stake. Nepots who are aware of this are careful to avoid 'shaming' the in-house relative through suboptimal performance. Hence, the nepot becomes responsible for protecting his/her own reputation as well as that of his/her relative(s). However, the additional demands brought about by the family referral recruitment do not only affect the nepot but also the relative who has acted as a facilitator. While the nepot is often in the spotlight and is expected to work harder than his/her peers, the facilitator is expected to ensure that he/she lives up to this standard. This appears to happen most markedly when a child is employed at his/her parents' workplace. The parents often take it upon themselves to monitor the performance of their 'child/co-worker', acting as secondary, substitute managers. Thus, the employer's control is extended while simultaneously this delegation of responsibility can unburden the manager. There are also examples of employers who explicitly expect and encourage this behavior-the parents should bring their childrearing responsibilities into the workplace and help mold their children into good workers:

Children often have their parents and mothers or, and [in this firm] it's mostly fathers [present in the workplace], so they, I suppose they have their orders [chortle]. It's really like having another employer. [\#7; rural; wood industry; family firm; small organization; male informant] 
If things are going a little slow to begin with, you know the parents will act discreetly in the periphery and help out so that it doesn't show so much. [\#18, medium-sized city, logistics; medium-sized organization; male informant]

The facilitator's responsibility actually starts before the nepot is in place at the workplace, namely through the choice of whom to recommend for a position. There is an element of self-preservation to this choice. In order to ensure that the recruitment will be a success, the facilitator will take care to only recommend suitable candidates. Should this turn out not to be the case, there is a risk of damage to their reputation within the organization, in addition to having to deal with a potentially incompetent coworker embodied by their own relative:

They'd never recommend someone they know doesn't measure up because... then they'd have a problem in the [work] group. [\#1; small city; technical industry; large organization; female informant]

\section{Social work environment}

The social work environment is where the values and risks of in-house family ties emerge with most clarity. The informants provide highly different interpretations and perspectives, whereby the same issue can be perceived as positive by some and negative by others. Some argue that the presence of family ties and other close social relationships in a workplace fosters a positive social work environment characterized by social cohesion among coworkers and a sense of caring (cf. Jones \& Stout, 2015):

[You] support each other, help each other in another way... ways that maybe you should for everyone but since there's a family tie... maybe you go that extra mile. [\#4; metropolitan; food industry; large organization; male informant]

Workers who feel comfortable at their workplace and like and trust their coworkers are likely to be more dedicated to their jobs and the organization. The intimate personal knowledge, or 'social putty', among coworkers and the family, like social ambience, strengthens the cooperation to the benefit of everyone's work situation as well as performance and productivity. This sense of familiness (van Hooft \& Stout, 2012) in both family firms and non-family firms becomes a feature of the general social environment within the organization, and therefore spills over onto other workers who do not themselves have in-family ties:

It's part of, how should I put it, the essence or the soul of the organization /.../These things are ingrained in the walls and it makes you treat each other in a way that makes it, well, it's very familial. [\#19; metropolitan; life sciences; family firm; medium-sized organization; male informant]

Some of the informants argue that one distinct benefit of in-house family ties is that they foster an open climate of communication. Because of the familial social dynamic and the personal knowledge and joint experiences going back in time, workers are not afraid of 
voicing their thoughts and opinions about issues that might have been sensitive to raise to someone else (cf. Ertug et al., 2014). This also goes for managers, who can feel that they 'dare' to be more direct in their leadership of relatives (cf. Hirschman, 1970). However, in the interest of maintaining the relationship into the future, criticism is also likely to be expressed in ways that do not potentially damage it. The (non-family) manager of a small family firm expresses this as follows:

You also try to communicate in a better way than you would if it didn't matter what this person thought of you at the end of the day /.../ If you're related then maybe you've had two or three arguments in your lifetime. It's just part of it and then you know you'll always make up afterwards. [\#31; large city; restaurant; family firm; micro-sized organization; female informant]

The familial social dynamic can be beneficial. However, underlying social processes connected to in-house family ties can also be expressed in negative ways. Some informants argue that having coworkers who are also related to each other can bring about a sense of awkwardness and discomfort within the workplace-a subtle tension in the social ambience:

It's really important that we have a good atmosphere, a good work environment, we should be able to talk about things /.../ and we shouldn't be stunted because someone's related to someone. [\#37; medium-sized city; state authority; medium-sized organization; female informant]

Moreover, instead of strengthening the communication, the presence of in-house family ties can become an obstacle to open communication and voice, as opposed to what is argued by Ertug et al. (2014). While the individuals who are related can communicate well, those who are outsiders from the 'family group' feel inhibited. For instance, workers may feel insecure or fearful that concerns they raise in conversation with a manager who has a partner at the workplace will not remain confidential but will rather be brought to the attention of the partner. This is expressed in relation to employees,

[There are] a mother and daughter on the same team. So if /.../ someone were to have an opinion about how one [of them] cooperated, performed their tasks, helped others or whatever, then there'd be another person who was very close to them so it would be like 'am I talking to one person or two people?' [\#36; medium-sized city; financial services; medium-sized organization; male informant]

as well as in terms of personal experience:

I understand the feeling, I've worked at places where someone was related [to someone at the workplace] and where you had to hold your tongue a little sometimes. [\#39, mediumsized city, state authority; medium-sized organization; female informant]

The perceived risk for such informal communication can damage the trust at the workplace and have a silencing effect on the climate of communication within the organization. 
This could have serious implications if problems are ignored, and potentially worsen, due to the failure to address them at an early stage. In addition, the communication problem can also detrimentally influence a nepot's work situation. For instance, he/she may feel excluded from social interactions.

In particular, workers without in-house family ties can find it very hard to express criticism regarding coworkers who are related to the manager, for example, when vertical ties are in place (Ertug et al., 2014). Out of insecurity or worry about how it might be received-for example, sparking conflicts of loyalty or backlashing against the person who raised the issue-critics prefer to keep their opinions to themselves. This also connects back to the crucial issue of asymmetrical power relations:

It can affect $\ldots$ the openness and honesty within the group. You have a hard time ... addressing problems because you feel like ... this person might ... gossip. [\#1; small city; technical industry; large organization; female informant]

A further aspect of the communication problem is related to leadership. Contrary to some informants who feel they can communicate more easily when there are personal relationships in place, others feel they become constrained in their leadership. In a scenario in which the incumbent staff has been used as a source of family referral recruitment, the manager may find himself/herself unable to criticize the nepot out of fear that this might cause a conflict with the facilitator:

It's harder to be a manager when things aren't working out /.../. And then there's probably a parent who might be the person you know ... who thinks 'that's not fair, she's great'. That can become a schism. [\#6; medium-sized city; restaurant; family firm; small organization; female informant]

In other words, the lack of voice can also emerge on the part of the employer/manager. Other examples of how the manager's role can be damaged include workers feeling mistrust toward the manager because of the recruitments, and nepots turning to the facilitators for instructions and ignoring the manager.

Among the disadvantages and risks associated with in-house family ties, adverse effects on the social work environment are what the informants emphasize the most. Many informants have experiences of and/or worry about social friction and personal conflict, as well as a hostile work environment more generally. These problems can appear in different constellations: among in-house relatives themselves; between these and other coworkers; or between either of these groups and the organization's management. Conflict among workers can have repercussions beyond the involved parties, affecting the other workers and their performance as well as the general social work environment.

The risk for tension or conflict among in-house relatives is related to intradomain conflict spillover and difficulties in separating or 'compartmentalizing' their professional and private roles (cf. Masuda \& Visio, 2012). Private matters may move into the work domain, or incidents at work may affect the workers' personal lives. Hence, there can be a risk that the private family relationship will be damaged by social transactions at work. There are also examples of relationship disintegration (separation/divorce). In 
such a situation, individuals may find it even harder to keep their private and professional affairs separate, and in many cases, the social work environment will be affected:

I worked for relatives myself... when I was young. And I thought it destroyed our relationship. He wasn't such a nice person at work. He was very hard /.../ this was my uncle /.../ At work /.../ you show sides of yourself that aren't your best ones... maybe. And of course it's difficult to just put it out of your mind. [\#6; medium-sized city; restaurant; family firm; small organization; female informant]

Another 'category' of tension is between workers and the management. The narratives are mostly focused on recruitment, layoffs, or situations in which disciplinary action is taken against an employee with in-house family ties. Emotional involvement and concern about their relatives result in protective reactions to changes, and can drive workers to explicitly or implicitly question the decisions of the organization's management:

The production manager, who's responsible for this recruitment together with me, told me at some point he'd been given sulky looks from this individual's [applicant's] mother, who also works here. And he noticed somehow that she was influenced by the fact that, well, her child hadn't moved forward in the [recruitment] process. [\#9; small town; technical industry; medium-sized organization; female informant]

The importance and sensitivity of in-house family ties become salient when employees with in-house family ties are affected by a certain negative change. Such situations can emerge when the employee has demonstrated a lack of work ethic, professionalism, or competence. Situations in which employees with in-house family ties underperform or allow their personal problems to interfere with work can be difficult to handle due to their sensitivity, as exemplified in the following narrative of a human resource manager at large workplaces within the private and public sector, respectively:

I got wind of a guy in the workshop /.../ [who] had a drinking problem. /.../ so I went to the foreman /.../ and said 'do you know you probably have a problem with alcohol on your team?'... He looked like he had no idea what I was talking about, so I told him who it was... And then we talked about this and that and nothing really came out of it, and he didn't really answer my questions. /.../ Later, someone told me that was his grandson. And then it was a little... sensitive. Of course. And he didn't tell me. And that was kind of clumsy of him, but I suspect he sort of panicked, he knew about it too and was also protecting [his grandson]. /.../ [\#13; large city; technical industry; large organization; male informant]

It is also more difficult for you as manager if your son is an employee and he doesn't do well - what's that conversation supposed to look like? [\#26; metropolitan; state authority; large organization; female informant]

Concerning dismissal, the informants virtually unanimously agree that family ties are irrelevant and have no impact on decisions and outcomes. Nevertheless, they can constitute a complicating factor in the process. The risk that the situation will become strained 
is enhanced, and when an in-house relative is affected, this may have to be managed in an 'extracurricular' way. Also, a tense social work environment, including rumor and speculation, seems to be the norm rather than the exception in such cases:

They think it's terrible and 'there should be a solution to this' and so on, and sometimes there are discussions about the order of dismissals. And sometimes you manage to make exceptions to this, and then there are discussions about why you made that exception and... was that person more important than another person and so on, [and] you need to have arguments and be able to motivate why you've done what you've done. [\#4; metropolitan; food industry; large organization; male informant]

There are also tensions that involve coworkers whereby one party has in-house family ties and the other does not. These conflicts tend to revolve around displeasure that is somehow related to the family connection. Examples include perceived injustices regarding, for example, scheduling, vacation-planning, or wage development. Actual or assumed special treatment forms the fundamental underlying issue in this. It can happen that employees feel that everyone is not treated equally. Particularly, if managers have relatives among the staff-vertical ties-there can be suspicions that these people will receive a more favorable treatment than others:

Wage determination is a hot potato. Scheduling work hours is a hot potato. It's a hot potato when you don't get the shifts you want as much as you want, and so on. [\#31; large city; restaurant; family firm; micro-sized organization; female informant]

I was approached and questioned whether it was the family relationship or the [person's] competence that had caused this person to receive this treatment that was seen as, not favoring, but, well, something like that. [\#36; medium-sized city; financial services; medium-sized organization; male informant]

This highlights the importance of asymmetrical power relations. If one relative is in a position in which he/she could potentially give unjustified benefits to a relative (cf. Padgett \& Morris, 2005), other workers may become suspicious regardless of whether or not there is de facto special treatment taking place. If employees think it could be a problem, this is enough to make it a problem. Moreover, distrust between employees and management is a problem in itself, whether it takes the form of open accusations and questioning of decisions or, worse, 'malicious tongue' becomes part of the daily life at the workplace. The outcome can be a hostile work environment and loss of efficiency when a significant portion of 'energy' is devoted to rumor and speculation:

If there's a risk that someone would say 'well he gets this because his father works here as a manager' or 'of course she gets this because I know she's married to this manager' and so on. It isn't fair to individuals and it isn't fair to the firm. [\#22; metropolitan; municipal administration; large organization; female informant]

However, some informants also describe that in-house family ties can entail a de facto risk of conflicts of interest or loyalty. The interests of the family can stand against those 
of the workplace and organization, which is why many of the informants regard family ties paired with asymmetrical power relations as highly inappropriate:

I think it's difficult to remain neutral when it comes to your own family. [\#5; medium-sized city; technical industry; large organization; female informant]

There can be a risk in firms where there's a higher share of kinship that it can be more difficult to navigate [the situation]... Making allowances, there's a risk that you make allowances in order not to hurt relatives' feelings... Other considerations than the purely rational ones come into play. [\#2; small city; technical industry; large organization; male informant]

\section{Individual Level}

A benefit of being family members who are also coworkers is having an understanding of each other's work situation based on experiential overlap. This insight promotes acceptance, and can help reduce friction in daily life in the home domain. Some informants also feel it is easier to find pragmatic and flexible solutions in social interactions with family members, which can be beneficial to both the individuals and the workplace when it comes arrangements in regard to, for example, scheduling, vacation-planning, childcare, and parental leave. However, from an employer perspective, other informants argue that the opposite can also happen. In-house family ties entail coordination difficulties, for instance, when both members of an employee couple expect to be able to take vacation at the same time.

An additional issue stemming from the intersection of the professional and private life domains is the lack of and/or need for compartmentalization. Many informants argue that some variety of separation of domains benefits both the private, personal relationships and the social work environment in the workplace. However, there are many accounts of work and private life becoming intermingled, primarily through work issues being discussed after hours. This blurring of boundaries between the times and places for work and private life, respectively, has both social and spatial implications (cf. Masuda \& Visio, 2012). Several informants see this as problematic and try to avoid this overlap of domains, either in order to protect the private domain and family life from interference or to shelter work from disturbances from their private life:

You want a sphere of your own. To meet other people. I think there's this need. You're together so much anyway, maybe with children and so on, and struggle and... so I don't think everyone's up to it [laughter], being together at work as well. [\#15; large city; architecture; medium-sized organization; male informant]

Another crucial set of problems on the individual level concerns one's career and livelihood. Several informants discuss the importance of personal networks for labor market opportunities. From a 'network maximizing' perspective, finding a job through one's family network and having one's relatives as coworkers is potentially problematic. An individual's total social network is likely to be significantly smaller under these conditions than a scenario in which there is no overlap between the professional and family 
networks. The latter situation is seen as preferable not only for reasons of career development but also because it is socially valuable. Career development within the organization can also present difficulties when, for instance, a person with in-house family ties strives for an executive position, given the above-mentioned problems related to asymmetrical power relations combined with family ties.

Being hired through family referral recruitment can constitute a convenient way of finding a job, especially for young people in need of gaining a foothold on the labor market (cf. Abdalla et al., 1995). However, it does not necessarily represent a well chosen strategy for their educational, personal, and professional development within a longer time frame:

The risk with those who come straight from high school is that more and more jobs demand higher education, and they can get really good at this function but it's more like, from a human perspective I feel like this is an easy and convenient solution for both parties if you can start making money early in life, but was this really what they wanted, have they challenged themselves, do they want this for the rest of their lives? It's quite an early choice they make. So I think that's kind of a pity. [\#36; medium-sized city; financial services; medium-sized organization; male informant]

Finally, a significant risk for the individual, raised by several informants across different geographical contexts, is economic vulnerability. Particularly on the household level, being employed by the same organization entails 'putting all your eggs in one basket' rather than spreading the risk. If there is an economic downturn and the employer is forced to make staff reductions, then there is a real risk that entire families will lose their livelihood:

If you're going to lay off two people and ... both of them have their family there [at the workplace] then of course it, it becomes a family tradition so to speak, and if you put all your eggs in one basket ... and both the mother and father work at the workplace and also the daughter and her husband ... And then the daughter and her husband get laid off, of course the mother and father are going to feel really awful about it, when the entire livelihood [comes from] the same place. And this is something very few people think about, that this can actually happen. [\#4; metropolitan; food industry; large organization; male informant]

\section{Concluding Discussion}

Sweden is an example of a modern Western society where practices commonly associated with non-democratic systems are presumed to have had their day. Yet, recruitment on the Swedish labor market is not entirely a matter of modern meritocracy and transparency, kinship-oriented practices can be found across lines of business and geographical contexts. The present study set out to shed light on how the values and risks associated with in-house family ties and family referral recruitment are perceived. Since this study rests upon 40 in-depth interviews with informants from varied labor market contexts with respect to organizational size and characteristics, location, and line of business, it provides broad empirical insight into the complexity and the role of in-house 
family ties. The findings reveal wide variation in perceptions and suggest that the pros and cons of in-house family ties can be considered at different levels of analysis ranging from strategic organizational issues to day-to-day operations and individual concerns. The complexity that is revealed is in itself a contribution to previous research because it adds nuance in the field of research. Moreover, this study shows that the same issue can be subject to conflicting views and that what is seen as a value or a risk is highly dependent on perspective: that of different actors, and of different organizational and societal levels.

From an organizational/employer perspective, in-house family ties can be a 'recipe for success' because of a high level of employee dedication and performance. However, the short-term convenience of using family referral recruitment as a shortcut in recruitment processes carries a risk of suboptimal worker-to-job matching, which can be detrimental to the longer-term development of the organization.

From a social work environment perspective, the benefits of social cohesion and 'familiness' (cf. van Hooft \& Stout, 2012) must be seen adjacent to the risk of friction and distrust among employees, which is particularly salient when vertical family ties (cf. Ertug et al., 2014) in the form of asymmetrical power relations are in place. The presence of in-house family ties can contribute to an accepting social ambience whereby workers feel they can openly voice their concerns (Hirschman, 1970), or an environment infused with potentially serious levels of insecurity and a lack of open communication.

Diverging aspects can also be raised from the perspective of individuals. Nepots who are able to secure a job through their family networks clearly benefit, but this often comes at the price of inflated pressure to perform and demonstrate that hiring them was not a mistake (Hernandes \& Page, 2006, in van Hooft \& Stout, 2012). Facilitators often put their personal reputation and prestige at work on the line by helping socially proximate individuals. For workers with in-house family ties, particularly spouses, the blurring of the boundaries between their private and professional lives can also cause work/life balance strain (Abdalla et al., 1994). A household in which several breadwinners share the same employer is also vulnerable to economic downturns, which could shatter the entire household livelihood. Employees without family ties within organizations where such ties exist are also affected. Career paths may be perceived as closed, or jobs as predefined for specific individuals. The same can be said for job applicants, who may feel discouraged from approaching potential employers or be less likely to succeed in finding work. The sheer suspicion that family ties are valued more highly than merits can prevent qualified people from applying for a job, thus contributing to lock-in effects and absence of new ideas (cf. Granovetter, 1973).

What is largely missing in the empirical material is a societal perspective. The interview narratives focus mainly on different facets of the organization and its (short term) needs. Family referral recruitment is argued to be, for example, as a pathway into working life for youth, and as a way of organizations 'caring' (CSR) for the local population and helping the labor market run smoothly. However, questions regarding (un)equal opportunities and (a lack of) transparency are not considered. Family ties are to some extent seen as facilitating pareto improvements, as the benefits or gains relatives experience are not disadvantageous to others—some win, but no one loses (cf. Riggio \& Saggi, 2015).

It is questionable whether there are any undisputable winners in this context. An organization where there is a notable feature of in-house family ties can become

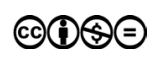


family-like in how it functions on a daily basis. Such an extension of the family (Zellweger et al., 2010) can not only be beneficial, but it can also be dysfunctional. The presence of relationships within the workplace that are personal and familial rather than professional generates a social dynamic of its own where the advantages tend to come with corresponding inverted disadvantages. Even in a scenario in which all parties perceive and experience in-house family ties in a positive light, there is a latent risk: it is not a problem-until it becomes a problem.

\section{Acknowledgment}

This research was supported by Riksbankens Jubileumsfond [grant number P13-1044:1].

\section{References}

Abdalla, H. F., Maghrabi AS \& Raggad, B. G. (1998). Assessing the perceptions of human resource managers toward nepotism. International Journal of Manpower, 19(8), 554-570. doi: http://dx.doi.org/10.1108/01437729810242235.

Agrawal, A., Kapur, D. \& McHale, J. (2008). How do spatial and social proximity influence knowledge flows? Evidence from patent data. Journal of Urban Economics, 64(2), 258-269. doi: http://dx.doi.org/10.1016/j.jue.2008.01.003.

Anderson, R. C. \& Reed, D. M. (2003). Founding-family ownership and firm performance: Evidence from the S\&P500. The Journal of Finance, 58(3), 1301-1328. doi: http://dx. doi.org/10.1111/1540-6261.00567.

Bashir, U. \& Ramay, M. I. (2010). Impact of stress on employees job performance. A study on banking sector of Pakistan. International Journal of Marketing Studies, 2(1,2), 122-126. doi: http://dx.doi.org/10.5539/ijms.v2n1p122.

Coyne, I. T. (1997). Sampling in qualitative research. Purposeful and theoretical sampling; merging or clear boundaries? Journal of Advanced Nursing, 26(3), 623-630. doi: http:// dx.doi.org/10.1046/j.1365-2648.1997.t01-25-00999.x.

Dyer, W. G. Jr. (2006). Examining the 'family effect' on firm performance. Family Business Review, 19(4), 253-273. doi: http://dx.doi.org/10.1111/j.1741-6248.2006.00074.x.

Ertug, G., Hedström, P. \& Kotha, R. (2014). Whose nepot should we hire? The influence of kin of initial employees on the survival of new firms. Available at SSRN: doi: http:// dx.doi.org/10.2139/ssrn.2504473.

Eurostat (2016). (June 15 2016). Retrieved from: http://ec.europa.eu/eurostat/web/structural-business-statistics/structural-business-statistics/sme.

Feldman, M. S., Bell, J. \& Berger, M. T. (2003a). Finding informants. In Feldman, M. S., Bell, J. \& Berger, M. T. (Eds.) Gaining access - A practical and theoretical guide for qualitative researchers (pp. 3-12). Walnut Creek: Altamira press.

Feldman, M. S., Bell, J. \& Berger, M. T. (2003b). Making initial contact. In Feldman, M. S., Bell, J. \& Berger, M. T. (Eds.) Gaining access - A practical and theoretical guide for qualitative researchers (pp. 23-34). Walnut Creek: Altamira press.

Fu, I-Pang (2015). Favoritism: Ethical dilemmas viewed through multiple paradigms. The Journal of Values-Based Leadership, 8(1), article 6. Available at: http://scholar.valpo.edu/ jvbl/vol8/iss1/6.

Förvaltningslag [Administrative Procedure Act] 1986. (June 23 2016). Retrieved from: http://www.riksdagen.se/sv/dokument-lagar/dokument/svensk-forfattningssamling/ forvaltningslag-1986223 sfs-1986-223. 
Granovetter, M. S. (1973). The strength of weak ties. American Journal of Sociology, 78(6), 1360-1380. doi: http://dx.doi.org/10.1086/225469.

Haugen, K., Holm, E. \& Westin, K. (2016) Släktband på arbetsplatsen: omfattning, erfarenheter och strategier. [Family ties in the workplace: extent, experiences and strategies]. GERUM Report 2016-05-25. Department of Geography and Economic History, Umeå University.

Jones, R. G. \& Stout, T. (2015). Policing nepotism and cronyism without losing value of social connection. Industrial and Organizational Psychology 8(1), 2-12. doi: http://dx.doi. org/10.1017/iop.2014.3.

Koivunen. T., Ylöstalo, H. \& Otonkorpi-Lehtoranta, K. (2015) Informal Practices of Inequality in Recruitment in Finland. Nordic Journal of Working Life Studies 5(3), 3-21. Available at: http://www.nordicwl.com/koivunen-ylostalo-otonkorpi-lehtoranta-2015informal-practices-of-inequality-in-recruitment-in-finland/.

Korang Adjei, E., Eriksson, R. H. \& Lindgren, U. (2016). Social proximity and firm performance: the importance of family member ties in workplaces. Regional Studies, Regional Science, 3(1), 304-3200. doi: http://dx.doi.org/10.1080/21681376.2016.1189354.

Masuda, A. \& Visio, M. (2012). Nepotism practices and the work-family interface. In Jones, R. G. (Ed.), Nepotism in Organizations (pp. 147-170). New York: Routledge.

Muchinsky, P. M. (2012). The nepotistic organization: What is this place and how do people make it? In Jones, R. G. (Ed.), Nepotism in Organizations (pp. 43-66). New York: Routledge.

Padgett, M. Y. \& Morris, K. A. (2005). Keeping it 'All in the family:' Does nepotism in the hiring process really benefit the beneficiary? Journal of Leadership and Organizational Studies 11(2), 34-45. doi: http://dx.doi.org/10.1177/107179190501100205.

Pearce, J. L. (2015). Cronyism and nepotism are bad for everyone: The research evidence. Industrial and Organizational Psychology, 8(1), 41-44. doi: http://dx.doi.org/10.1017/ iop.2014.10.

Qu, S. Q. \& Dumay, J. (2011). The qualitative research interview. Qualitative Research in Accounting \& Management, 8(3), 238-264. doi: http://dx.doi.org/10.1108/ 11766091111162070.

Reed, C. M. (1988). Anti-nepotism rules and dual career couples: policy questions for public personnel administrators. Public Personnel Management, 17(2), 223-230. doi: http://dx. doi.org/10.1177/009102608801700210.

Riggio, R. E. \& Saggi, K. (2015). If we do our job correctly, nobody gets hurt by nepotism. Industrial and Organizational Psychology, 8(1), 19-21. doi: http://dx.doi.org/10.1017/ iop.2014.5.

Saldaña, J. (2016). The coding manual for qualitative researchers. London: Sage.

van Hooft, E. A. J. \& Stout, T. (2012). Nepotism and career choice, job search, and job choice. In Jones, R. G. (Ed.), Nepotism in Organizations (pp. 67-92). New York: Routledge.

Vveinhardt, J. \& Petrauskaité, L. (2013). Intensity of nepotism expression in organizations of Lithuania. Management of Organizations: Systematic Research, 66, 129-148. doi: http:// dx.doi.org/10.7220/MOSR.1392.1142.2013.66.9.

Vveinhardt, J. \& Zymgantaite, R. (2015). Influence of CSR policies in preventing dysfunctional behavior in organizations. Procedia - Social and Behavioral Sciences, 205, 340-348. doi: http://dx.doi.org/10.1016/j.sbspro.2015.09.095.

Zellweger, T. M., Eddleston, K. A. \& Kellermans, F. W. (2010). Exploring the concept of familiness: Introducing family firm identity. Journal of Family Business Strategy, 1(1); 54-63. doi: http://dx.doi.org/10.1016/j.jfbs.2009.12.003.

Žulová, J. (2015). Legal issues associated with nepotism in the workplaces in the Slovak republic. European Scientific Journal, 1, 10-17. Available at: http://eujournal.org/index. php/esj/article/viewFile/6675/6408. 